Journal of Teacher Education for Sustainability, vol. 19, no. 2, pp. 107-120, 2017

\title{
The Resolution of Conflict between Teacher and Student: Students' Narratives
}

\author{
Grazina Ciuladiene and Brigita Kairiene \\ Mykolas Romeris University, Lithuania
}

\begin{abstract}
The important thing for teachers is to solve conflicts with students correctly and effectively without damaging the relationship, losing the cooperation with students or disrupting educational process. Although there is a great concern about the way a teacher manages students' behaviour, there is very little relevant data concerning teacher-student conflict. The article aims at revealing the characteristics of conflict resolution between students and teachers from the students' point of view.

To investigate the process of conflict between a teacher and a student, a case study method was used. Respondents were asked to recall a conflict occurring between them and a teacher during the school years, describe how the incident was handled, and the consequences of it. The number of respondents constituted 30 students.

Students and teachers actually engage in a range of behaviours. In accordance with the theoretical framework, the four behavioural categories were grouped. Students reported that during the teacher-students conflict a full palette of strategies (dominating, integrating, accommodating and avoiding strategies) was used. Findings revealed that forcing was expressed by arguments, involving a third party and aggression. Avoiding was expressed by crying, avoiding the contact. Accommodating was expressed by pretending and giving in. Apologising, making a compromise, compensation, talking about the problem were examples of an integrating strategy.

The results indicated that participants reported 28 behavioural reactions to a classroom conflict. Among them, 12 were those of teacher engagement, and 16 of student engagement. In line with the conglomerated conflict behaviour framework, students reported that both conflict parties (students and teachers) in the case of active student position engaged in more than one type of behaviour in response to a single incident. Understanding students' experience would allow teachers to better respond and manage students' reactions, as well as help teachers prevent behaviours such as aggression and promote other behaviours such as motivation.
\end{abstract}

Keywords: conflict, reason, resolution, student, teacher 


\section{Introduction}

Considered to be a key indicator of subjective sustainability, the socio-emotional competency includes the ability to find a protective internal mechanism in complicated situations and the ability to communicate positively. Possessing such competency requires one to create and keep friendship relations (Kuurme and Carlsson, 2010). After all, the idea of sustainable development is the idea of harmonious coexistence of subjects, societies, and the surrounding world (Makarevičs, 2008). The necessary socio-emotional competences are acquired by students under supervision of teachers. M. Sakk (2015, p. 100) has emphasised "the initial and basic role of the teacher is to form learners' learning skills, emotional competency and social skills so that they could cope at school”.

It is being emphasised in the pedagogical literature that a harmonious relationship between students and teachers based on mutual respect, understanding, kindness and cooperation is essential for a positive school climate and the success of education (e.g., Aramavičiùte, 2005; Pagliaro, 2011). Without the cooperation, the school or the individual members classroom cannot function (Ozgan, 2016: 147). It is important for students to gain a positive experience from learning. Socialisation into the existing reality cannot serve sustainability if there are too many signs of a negative conflicting relationship.

However, some studies (e.g., Archambault, Kurdi, Olivier, and Goulet, 2016; Čiuladienè, 2013) have revealed that the reality of school is characterised not only by constructive but also by destructive interactions. Teacher-student relationships dominated by a conflict are negatively associated with student behavioural and affective engagement in learning. Moreover, conflict in the teacher-student relationship significantly and positively correlates with peer victimization (Archambault et al., 2016).

However, the studies carried out concerning conflicts between teacher and students are quite limited (Dogan, 2016). Based on quantitative data, the researcher has argued that teachers tend to apply respectively domination, reconciliation, integration, avoidance and compromise strategies for the resolution of conflicts experienced between a teacher and a student. However, qualitative research has explored negative ways in which teachers perceive and manage conflicts and the disputants. Langaretti and Wilson (2006) found that the majority of responses used by teachers in the playground were contending strategies, including verbal abuse and physical involvement, a less frequently used strategy was withdrawal (inaction, referring to other teacher, ignorance and sending away), the least common approach was problem solving. In the study, none of the teachers used smoothing or compromising.

Teachers' conflict management needs to be studied to improve the management. In fact, only a few studies have been conducted on this issue in Lithuania. Whereas conflict handling behaviour of individuals is directly related to culture (Ohbuchi, Fukushima and Tedeschi, 1999), this study is based on narratives of Lithuanian students. The study aims at displaying the main characteristics of teacher-student conflict management. The questions to be answered are the following: 1) what teacher's behaviour is associated with the cause of teacher-student conflicts? 2) What reactions are used when a conflict between a teacher and a student occurs? 


\section{Theoretical Framework}

A set of three concepts to explain the nature of conflict is used here after Mayer's (2000) explanation of the dynamic of conflict. Three dimensions restrict to focus on the thoughts, feelings and behaviours related to a conflict issue. Thoughts about failure to satisfy the interests and a situation concern a cognitive (perceptual) dimension. The assessment of a situation is framed by person's beliefs and perception about him/herself and the other party, interpretation of facts and data, attribution of motives and beliefs about the other party's intentions. Besides, emotional reactions also appear (an emotional dimension). From a conflict dynamic perspective, it is critical to assess the conflict from the emotional point of view to understand what emotions the parties are carrying in relations to the conflict, and how these emotions may affect the resolution process. In addition to perception and feelings about a conflict, parties also make choices on how to behave in response to the conflict (a behavioural dimension). Over and above, one party's behaviour may trigger another party's response, with the first party quite unaware of how their behaviour is contributing to the problem (Furlong, 2005, p. 169).

Based on this dimension model, a conflict is to be defined as a situation when two or more parties experience emotional frustrations and interaction struggles due to perceived incompatibility of interests. Personal interests can affect the decision to use a particular strategy or strategies in order to manage a conflict (Wilmot and Hocker, 2001).

Wilmot and Hocker (2001, p. 130) defined conflict resolution strategies (styles) as patterned responses, or clusters of behaviour that people use in conflict. Conflict researchers classify conflict resolution strategies in different ways. However, most researchers use a five-strategy approach defined by Kilmann and Thomas, which includes collaboration, accommodation, competition, avoidance, compromise. There are several ways in the literature to characterise these five strategies by combining them into two grid dimensions, such as concern for self and concern for the other (Rahim, 1986); activity and passivity; cooperativeness and assertiveness (Wilmot and Hocker, 2001); appropriateness and effectiveness (Gross and Guerrero, 2000); and distributivity and integrity (Van de Vliert et al., 2004).

Avoidance represents a low level of concern for self and a low level of concern for the other; it is marked by passivity; it is uncooperative, ineffective, and inappropriate. Accommodation represents a low level of concern for self but a high level of concern for the other (it is a strategy by which individuals give up their own needs and conform to what the other wants). It is a passive and indirect response. It represents a high level of cooperativeness; in this strategy, protecting the relationship is the most important outcome. Individuals who use this strategy are perceived as appropriate but not effective. Competition (dominating / forcing) represents a high level of concern for self and a low level of concern for the other. Competition cannot be used without an activity - there is a need for active work and high-energy involvement. It is defined as that of high level of assertiveness and as uncooperative one. Collaboration (problem solving / integrating) represents a high level of both opponents' concerns (for the collaborating strategy identifying a mutual satisfying solution is the goal). It is an active strategy; it expresses a high level of assertiveness by cooperativeness. It is both effective and appropriate (it provides each disputant with access to the other person's perceptions of incompatible goals, thereby enabling them to find a solution that integrates the goals and needs of both 
parties). Compromise is a middle ground, where there are moderate degrees of concern for self and concern for the other. Compromise can be either active or passive, depending on its type. This strategy is also seen as moderately direct and cooperative, effective and appropriate.

Conflict resolution strategies may take different methods (tactics forms). Tactics are individual moves people make to carry out their general approach (Wilmot and Hocker, 2001, 130-150). The classification differs from one author to another. In reference, it could be stated that all of the avoidance tactics involve refusing to engage in the conflict. Although competition comes in many tactics, its function is always to pursue one's concerns at the expense of the other concerns. All competitive tactics involve pressuring the other person to change. Collaboration involves descriptive and disclosing statements and soliciting disclosure and criticism from the other party.

In daily life, these basic reactions are used as components of more complex reactions. For those complex reactions of a conflict issue, the term of conglomerated conflict behaviour may be used (Van de Vliert et al., 2004). The conglomerate perspective posits that any reaction consists of multiple components of conflict behaviour, and that these components moderate each other's effect on the substantive and relational outcomes of the conflict. The theory of conglomerate conflict behaviour states that the components of conflict behaviour should be considered as interrelated. Conglomerations of escalation contending and de-escalation accommodating, integrating, or avoiding might well be more effective than contending in and of itself (Euwema, van de Vliert, Bakker, 2003).

\section{Procedures}

The instrumentation and procedures replicated those of Horan, Chory and Goodboy (2010) where a questionnaire format was employed. Participants were asked to recall the conflict with a teacher they experienced at school. The first question asked about teacher behaviour (what did the teacher say or do that made you think he/she were unfair?). Next participants were asked to describe their feelings after this unfair act. Finally, they were asked to write how they reacted to this unfairness, what way a teacher reacted to their response.

\section{Data Analysis}

A method of involving data analysis is the content analysis (Berg, 2007). Transcriptions of the provided teacher-student conflict situations were read several times with the purpose of extracting important statements, which were directly related to the variation of conflict causes and resolution strategies.

Answers were deductively coded according to a set of three categories, which were derived from dimensions of the conflict process: perception of cause, feeling to an unfair teacher's action, and actions (those of teacher and student) aiming to resolve the issue. Content analysis helps teachers interpret thoughts, feelings and actions expressed by young people dealing with a conflict in the educational setting. Each behavioural response constituted a separate unit. Then, after in-depth analysis of the responses, they were organised in accordance with various coding schemes. Firstly, a two-category scheme was decided upon. Passive orientation was defined as inaction /acceptance. Active orientation occurred when students took actions to express their dissent. Secondly, a four- 
category coding system was agreed upon. It was identified that four conflict resolution strategies were used: integrating, forcing, avoiding and accommodating. Forcing focuses on wanting to win the conflict (to force the violation) and unwilling to reconcile. Forcing assumes victory of one party at the expense of the other. Accommodating emphasises the preservation of relational concern by obliging to others' desires. Integrating emphasises both the resolution of the conflict and the preservation of the relationship. Integrating style means satisfying the goals and needs of both parties in conflict. Avoiding represents withdrawal from the situation and avoiding the other party.

\section{Participants}

The data were collected from students of Mykolas Romeris University. Participation in the study was voluntary, and students had time in class to complete the task. The investigation was led under requirements of the social research ethics: respondents were informed about the objectives and contents of the survey, confidentiality was kept to preserve personal data of the respondents and voluntary participation guaranteed by asking of personal consent to participate with the possibility to withdraw from it an an moment. The questionnaire was self-administered and required approximately 30 minutes to complete.

The number of respondents constituted 30 students. There were 22 females, 5 males and 3 unidentified. The student respondents were graduates and postgraduates. Their average age was 24.9 .

\section{Limitation of the Research}

The cases of the conflicts between teachers and students, which are analysed in the article, are presented from the perspective of one side of the conflict - student's; therefore, it is taken into account that the conflicts, which were the most memorable to students, are presented, especially, when the beginning of a conflict was related to, in students' assessment, inappropriate actions of a teacher.

\section{Findings}

\section{Student's Perception and Feelings regarding a Conflict Situation}

In the opinion of students, the case of a conflict arises from the unfair assessment of the student's work (by a lower grade than a student expected). On the basis of the presented case descriptions, two subcategories can be distinguished:

1) An assessment is not objective. In the opinion of a student, teachers, when assessing, did not adhere to the principles of assessment $(10,18)$. The cases, when a student marked a negative attitude of a teacher towards a group (teachers practiced a different assessment system towards individual students), were classified in this subcategory $(9,1,22,14,13,2,20)$. The students claimed that the teachers assessed differently students, such as freshmen (9), students who were low achievers (22), not belonging to the category of "teacher's pets” $(13,14,22)$ or simply "certain students” $(17,10)$. 
2) An assessment does not correspond to reality (in the opinion of a student) - a teacher did not give a grade which is due to a student $(8,18)$. For example, a student is accused of cheating or lying. However, not due to the fact that a teacher had evidence, which substantiated such a decision, but because s/he thought like that - teacher's decisions were based on an initial preconceived negative attitude. A teacher, on the basis of his own invented unreasonable presumptions, punished a student by lowering his/her grade (1) or by refusing to enter a grade, which was due to a student, into the registry (8). Consequently, the second subcategory is comprised of the cases when a negative attitude of a teacher is not towards a group, but only towards a student- a teacher does not believe in the student's integrity and / or does not trust his/her abilities, does not believe that a student performed the task him/herself and acquired the necessary skills to perform the task $(8,18)$, does not believe that a student is able to solve problems related to education (19). On the other hand, it should be borne in mind that the label of "a negative attitude of a teacher" reflects a student's approach, which may differ from a real attitude of a teacher towards a student. During one of the conflicts, three students made the same number of mistakes in the task they had performed. Two students received the same assessment, whereas the third one received a grade which was lower by one point. When the latter student inquired the teacher why his assessment was different, the teacher responded that, in this way, he wanted to encourage him to make even a greater effort. The case may be interpreted controversially it could have been that the attitude towards the student was extremely positive (the student was assessed as the one who was more gifted than his classmates). However, the student, when perceiving the situation as conflictual, felt injustice, great disillusionment towards the teacher, and feels grievance up till now, when a few years have passed since the event (2).

Having been assessed, in their opinion, incorrectly, students felt grievance $(18,22)$, felt bad $(2,14,18)$, felt humiliated, underestimated $(1,9,10,13,18)$, lost their motivation to learn (9), as well as felt anger, disappointment $(4,8,9,10,20)$.

An analysis of the cases has enabled the authors to distinguish one more cause of conflicts. It is an inadequate reaction of a teacher towards the situation $(7,11,16)$. Here, two subcategories have also been distinguished:

1) Unjust punishment imposed by a teacher. In one of the cases (16), a conflict started when a teacher learned that one student (8 years old) would sell children's jewellery to other classmates. He imposed 4 punishments on the student: he informed the headmaster of the school about the situation, assessed the student's behaviour by giving a negative grade, scolded him in front of all the schoolmates and informed his parents. In this case, the teacher did not assess the student's transgression and did not choose a punishment which was adequate to the transgression and effective; he disregarded a circumstance that the student did not have sufficient knowledge and skills to assess the impropriety of his actions, because he was a second form student. The student's reaction towards numerous punishments was expressed by a deep sorrow, the feeling of hopelessness, the fear regarding negative reaction of parents and punishment (16). 
2) Psychological abuse towards students. Such teacher's actions as insulting, offending, humiliation of a student $(11,15,19)$, shouting at a student without providing appropriate information on the performance of a task (6), threats of punishing (20) were classified under this subcategory. Due to such teacher's behaviour, students lost their motivation to learn and commenced skipping school (19), felt humiliated, felt shame (11), felt offended (15), felt sorrow, annoyance $(20)$.

\section{Teacher-Student Conflict Resolution Strategies}

The results indicated that participants reported 28 behavioural reactions to a teacherstudent conflict. Among them, 12 were those of teacher engagement, and 16 of student engagement. Table 1 provides the results of data content analysis.

Table 1

Behavioural Responses to Teacher-Student Conflict

\begin{tabular}{|c|c|c|c|}
\hline $\begin{array}{l}\text { Cate- } \\
\text { gories }\end{array}$ & Behaviour & Student actions & Teacher actions \\
\hline \multirow[b]{2}{*}{ 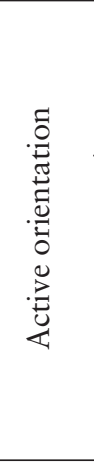 } & Integrating & $\begin{array}{l}\text { Apologises } \\
\text { Clarifies the situation by asking } \\
\text { additional questions } \\
\text { Compromises }\end{array}$ & $\begin{array}{l}\text { Apologises } \\
\text { Proposes compensation } \\
\text { Clarifies the situation by listening to } \\
\text { a student, asking additional questions }\end{array}$ \\
\hline & Forcing & $\begin{array}{l}\text { Argues } \\
\text { Blames a teacher } \\
\text { Stops effort } \\
\text { Lies } \\
\text { Involves parents } \\
\text { Involves administration } \\
\text { Threatens the teacher behind } \\
\text { his/her back }\end{array}$ & $\begin{array}{l}\text { Argues } \\
\text { Gives a scolding } \\
\text { Reduces grade } \\
\text { Involves parents } \\
\text { Involves the administration } \\
\text { Threatens } \\
\text { Humiliates }\end{array}$ \\
\hline \multirow{2}{*}{ 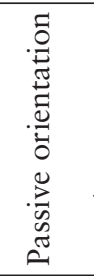 } & Avoiding & $\begin{array}{l}\text { Cries } \\
\text { Comes out of the class } \\
\text { (slams door) } \\
\text { Does not communicate } \\
\text { Changes class }\end{array}$ & $\begin{array}{l}\text { Takes no comment (does not } \\
\text { speak on the subject) }\end{array}$ \\
\hline & $\begin{array}{l}\text { Accom- } \\
\text { modating }\end{array}$ & $\begin{array}{l}\text { Descends / complies } \\
\text { Does nothing }\end{array}$ & Descends / complies \\
\hline
\end{tabular}

Both students and teachers actually engage in the range of behaviours. In accordance with the theoretical framework, the four behavioural categories were grouped. Students reported that during the teacher-students conflict a full palette of strategies (dominating, integrating, accommodating and avoiding strategies) was used. Findings revealed that forcing was expressed by arguments, involving a third party and aggression. Avoiding was expressed by crying, avoiding the contact. Accommodating was expressed by pretending and giving in. Apologising, making a compromise, compensation, talking about the problem were examples of integrating. In line with the conglomerated conflict behaviour framework, students reported that both conflict parties (students and teachers) in the case of active student positions were engaging in more than one type of behaviour in response to a single incident. 
An analysis of the cases of the conflict between a teacher and a student enabled the authors of the research to systemise the obtained findings and create a conflict resolution algorithm determining the connection between the actions (selected strategies) of conflict participants and the consequence (result) of a conflict (Fig. 1).

The course of a conflict was determined by an approach towards a conflict taken by a student - passive or active and, consequently, a conflict resolution strategy. If from the very beginning (during a conflict identification stage) a passive approach is chosen, the conflict is not solved, whereas the initial reaction of a student towards the conflict that manifests through negative feelings, which s/he experiences - mortification when seeing injustice $(7,16,21)$, the feeling of being humiliated, underestimated (17) -, remains unaffected sometimes even after a long period since the conflict occurred (the student does not communicate with the teacher (17), (7)).

An example of the passive approach of a student towards a conflict could be the case when a student was asked to come up to the blackboard to solve a problem, and when s/he came up to the blackboard and erased what was written on it, the teacher told him to sit down and entered a two for mathematics into the registry (7). An inadequate reaction of the teacher towards the situation and the further actions of the teacher, namely during a parent meeting the teacher told his parents that the student was not able to solve the problem, determined the negative reaction of the student, due to which s/he took a passive approach and decided not to take any actions. The negative feelings of the student, due to the incorrect behaviour of the teacher, remained and are experienced up till now, after the passage of a few years. In this case, the conflict remains unresolved the teacher became even less respected and disliked by the students, whereas the student feels grievance up till now (7). Therefore, by taking a passive approach towards the arisen situation, the student failed to create an opportunity for the teacher, whose actions, actually, became the cause of the conflict, to learn about the student's experiences and, likely, to assess his/her own actions. In this situation, the student's reaction towards the conflict was the only thing on which it depended whether the conflict would be resolved.

When analysing the cases, it became clear that when a student chose an active approach towards the arisen situation, an opportunity to resolve a conflict increased significantly $(1,5,8,9,10,15,27)$. The first strategy, which is chosen by a student showing an active student's approach towards an arisen situation, is integrating. A student him/herself chooses an opportunity to clarify with a teacher when s/he is dissatisfied with the assessment issued by a teacher $(1,2,3,4,5,7,8,9,10,12,13,14,18,20$, $22,23,24,25,26,27,29,30)$. As the findings of the study demonstrate, a strategy and a method chosen by a student - to clarify with a teacher on his/her own - tends to be successful only in those cases when another side of the conflict, a teacher, applies the same integrating strategy (for example, listens attentively to the student's needs $(1,5)$ ). The case when a student, who was dissatisfied with the assessment of the performed task, asked the teacher to comment on the assessment could be such an example. At first, the teacher did not respond to the student's needs and ignored the request by failing to present a clarification, due to that fact the student became angry and refused to perform the further tasks. However, when the teacher, nevertheless, agreed to explain the assessment criteria (responded to the student's needs), the student listened to the teacher's observations, understood the mistakes, which s/he made while performing the task, and felt satisfaction - the conflict was resolved. When evaluating the sequence of the applied strategies, the first strategy (integrating), which was chosen by the student, 
was appropriate however, the course of the conflict resolution depended on the teacher's reaction towards the strategy applied by the student. Due to the fact that the initial reaction of the teacher was not positive and not responding to the student's address, there was no positive conflict resolution. Only when the teacher changed his/her strategy by responding to the student's needs to learn the assessment criteria and commented on the performed task, the conflict was resolved and, likely, did not have a negative effect on the further relationships (5). This example also shows that a teacher is the leader of teacher-student mutual relationships due to the instruments of power s/he possesses; therefore, in active student-student interrelationships a teacher plays a key role.

Despite the fact that the examined cases, when students record a conflict due to inappropriate actions of a teacher, show a negative attitude of a teacher towards a student, the case, when the beginning of a conflict is related to the lowering of a grade, which reflects good teacher's intention, deserves attention. In the case under examination, after three students performed a task, they made the same number of mistakes. Two students received the same assessment, whereas the third one received a grade which was lower by one point. When the latter student inquired the teacher why his assessment differed from that of other students, the teacher responded that he wanted to encourage the student to make even a greater effort, i.e., to motivate. At first glance, it seems that the teacher's intentions are good; however, the further course of the conflict shows that not only did the student have no intention to make a greater effort, but he felt injustice, great disappointment regarding the teacher, whereas grievance is felt up till now, after the passage of a few years (2). When the conflict occurred, an active approach of the student, which was taken by him, and the appropriate method, clarification, did not create preconditions to resolve the conflict because the response chosen by the second participant of the conflict, teacher, to use the instruments of power he possessed when motivating the student, not only failed to contribute to the resolution of the conflict, but deepened it even more.

In those cases when a student's clarification with a teacher is unsuccessful and a conflict remains unresolved some students become disappointed and take no actions (4, $12,13,14,18,20,22)$; however, others keep on taking an active approach and try other methods to resolve a conflict $(8,9,10)$. Addressing other persons - addressing the school administration (headmaster, deputy headmaster and the like) - can be identified as an effective method of conflict resolution chosen by a student. In all the analysed cases, when a student addressed the representative of the school administration, i.e., a person who possessed more power than a teacher, a conflict was resolved. In addition, it became clear that in all the analysed cases a student had a particular proposal how to resolve a conflict. Therefore, in this case, not only did the student take an active approach by deciding to act, but also became engaged in the conflict resolution him/herself as a resolver with his/her proposal, although not possessing the power of decision to implement that proposal. The student engaged the representative of the school administration in the conflict resolution essentially only due to the fact that the latter possessed the instruments of power (levers), for example, the student addressed the headmaster requesting to substitute the teacher (9), or the one who had an opportunity to perform the function of assessment, the deputy headmaster, requesting to assess the performed task and decide whether the teacher assessed appropriately $(8,10)$.

Students sometimes resolve a conflict without addressing third parties, who possess power, but exercise the power they possess by uniting themselves. The conflict began 
because of a teacher's reaction towards the student's behaviour - when a student, to whom it was irrelevant to take a biology examination, refused to perform a task, the teacher began to insult, to bumiliate the student in front of all the group mates with delight (15). The student became irritated and went out of the classroom. The next day all the students from his form, by showing solidarity with the injured student, locked themselves in the classroom and refused to let the teacher into the classroom. Such unification of the students to resist the improper behaviour of a teacher assisted in resolving the conflict - the teacher apologised to the student, whereas the student also apologised. However, in the future the teacher lost the respect of his students. This situation, like wise other cases, which have been examined before, shows that if a teacher does not respond to a student's need to clarify an arisen situation, it can be done only by the persons who possess a greater power than the teacher (the representatives of the school administration) or the plurality of persons (students).

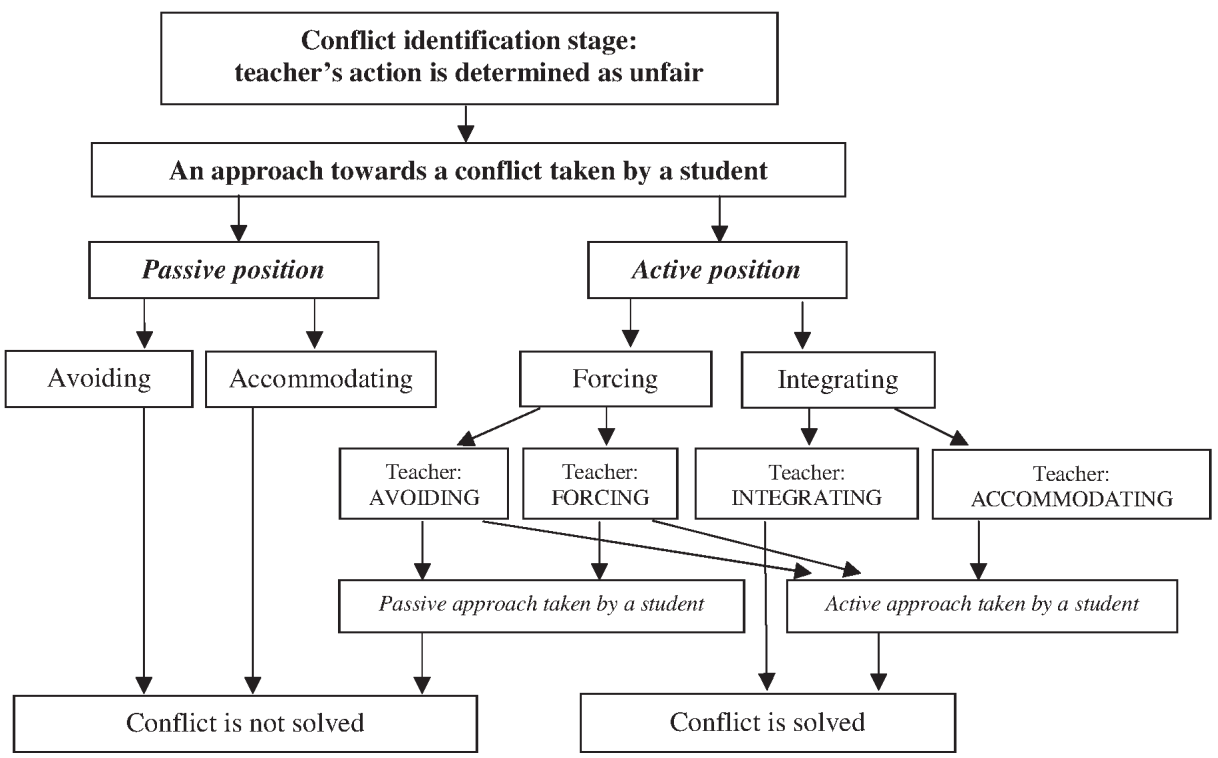

Figure 1. The actions (selected strategies) of conflict participants

\section{Discussion}

Conflict researchers have shown that controversy has positive effects in certain cognitive processes and that conflicts of a cognitive order are more related to group productivity than those of an affective order (Sauquet, Bonet, 2003). Conflict helps one to solve problems, improve work effectiveness and strengthen involved parties' relationships (Tjosvold, Hui and Law, 2001). However, it is of great importance that attempts are made to resolve a conflict. Effective conflict management encourages motivation, enhances morale and promotes individual and organisational growth (Rahim, 1986). Ineffective conflict management, in contrast, generates more conflict and negatively affects the organisation as a whole. Children who report a frequent conflict with teachers are more likely to present psychosocial difficulties, such as aggressive behaviours, depression, loneliness, anxiety, and low self-esteem (Archambault et al., 2016). 
The aim of this study was to investigate students' opinion on teacher-student conflict reasons and students and teachers' behavioural reactions to conflict. Due to the fact that the analysed conflicts are presented from the viewpoint of a student, consequently, the beginning of a conflict, i.e., certain actions of a teacher, are also identified as the cause of a conflict by the students due to the experienced negative feelings towards an arisen situation. The analysis of conflict causes enabled the authors to reveal situations related to the teacher's actions, which were perceived as the beginning of a conflict by students, but not necessarily by teachers. The identification of the causes of a conflict created an opportunity for teachers to observe their own behaviour, actions, which they possibly disregarded and did not foresee, the experiences students went through because of their actions "through the student's lens".

The present study showed that when resolving a conflict between teachers and students, which was recorded by a student, who felt bad due the teacher's actions, the decisive criterion, which determined the outcome of a conflict, was a student's approach towards an arisen conflictual situation. Regardless of conflict causes, if a student takes a passive approach, i.e., takes no actions in order to resolve a conflict, the course of the conflict is paused and the student, who recorded the conflict, remains with the same negative feelings, which s/he experienced when recording the conflict. If a student chooses an active approach, opportunities to resolve a conflict increase significantly; however, a crucial factor, which determines the further course of the conflict, is the teacher's actions which either respond or fail to respond to the student's needs.

The findings demonstrated that both teachers and students' behavioural reactions ranged from aggression to withdrawal. Besides, students tended to use avoiding quite often. This tendency was in accordance with other investigations. Avoidance occurs in a superior-subordinate relationship when the former makes a decision that the latter does not like but feels that he or she has no choice but to comply with the wishes of the superior (Rahim, 1986). Davidson, McEwee and Hannan (2004) have argued that lower power participants are often more concerned about preserving their relationship with their superior (i.e., using obliging strategies) than winning a negotiation, especially when their superior has influence over their future well-being. This is especially true when superiors are authoritarian and can use coercive power to control the behaviour of subordinates. Coleman (2006, p. 124) has stated that the overwhelming evidence seems to indicate that the powerful tend to like power, use it, justify having it, and attempt to keep it. High-power decision makers have little interest in expanding resources (integrating) as they can achieve their goals by using dominating strategies.

Teacher's domineering (forceful) conflict behaviour is not consistent with the principles of sustainability as the sustainable school adopts the democratic and participatory process of decision-making - the sustainable school adopts participatory and student-centred approaches that develop students' skills, abilities and qualities for critical thinking, intercultural understanding and willingness to participate (Kalaitzidis, 2012). Moreover, education for sustainable development aims at promoting abilities such as decision making, conflict management, initiative for action, personal and social communication abilities and the development of mutual trust and acceptance of difference (Mitakidou and Tamoutseli, 2011). Thus, teachers should embrace collaborative style and power sharing.

The findings are in line with the other studies indicating the importance of teacher's conflict resolutions skills, and revealing their insufficient level. For instance, Okeke and Mtyuda (2017) have acknowledged that only $39 \%$ of the teacher participants are efficient 
at disciplining students. Ortega and Fuentes (2015) have concluded that the quality of teaching depends on the quality of communication in the classroom. In the study, $53.3 \%$ of the respondents believe that communication skills are worked on sufficiently, $80 \%$ believe that these skills are not acquired. Similarly, Ficarra and Quinn (2014) have indicated that teachers have identified classroom management as an area for which they need additional on-site training that will establish or further develop skills not sufficiently addressed in pre-service programmes. According to Kuurme and Carlsson (2010), a routine hierarchical working system and bad relations diminish the quality of school life. The researchers argue that "a human being cannot develop into an authentic person with repressive pedagogy, when being under the will of an external authority and dealing with it constitutes the core of the experience"(p. 72). However, M. Sakk (2013) has found in her investigation that the role of the teacher does not allow learners to express their opinion or thoughts as the teachers are focused on teaching their subject and on learners' learning (in its narrow meaning) rather than on the social development of children.

Dogan (2016, p. 210) has cautioned that preferring mostly the strategy of domination by teachers may be evaluated as clamping down on teachers. Wrong choices made by teachers negatively affect the psychology of students and teachers as well as the relation between teachers and students, and it does not contribute to a solution. The students might think that all communication methods are blocked with the teacher as soon as the teacher applies the domination strategy in conflict situations. Johnson and Johnson (2006) have indicated that the imposed resolution refers to the conflict suppression, and underlying grievances are not resolved and positive long-term relationships among parties are not established.

Johnson and Johnson (2006) have listed a plenty of positive school conflict outcomes, such as focusing attention on problems to be solved, clarifying disputants' identity and values, revealing how disputants need to change, increasing higher-level cognitive and moral reasoning, increasing motivation to learn, providing insights into other perspectives and life experiences, strengthening relationships, adding fun and drama to life, increasing disputants' ability to cope with stress and be resilient in the face of adversity, and increasing general psychological health. However, the constructive results depend on the competencies parties apply in managing their conflicts. The most productive conflict management strategies are those that tend to take into account the interests of both parties, and also those avoidance strategies tend to be less productive. Integrative solution of interpersonal conflicts requires mutual facing of the problem and taking part in mutual problem solving discussions in order to reach the rational agreement, which is also a mutual advantage of both sides of the conflict (Johnson and Johnson, 1994).

For the resolution of student conflicts with teachers, the strategy of integrating should be a more common choice. In terms of effectiveness, this strategy produces the most positive results: as the opponents get to know themselves better, their relations improve and the cause of the conflict can be eliminated more easily. If the primary actions taken fail, other ways of resolving the conflict should be sought. The variety of ways to implement the integrating strategy provides real possibilities for solving even a prolonged conflict. Constructive conflict resolution depends on the ability to choose from a wide repertoire of strategies and tactics to support a specific desired outcome (Wilmot and Hocker, 2001, p. 130). Resolving conflict in a constructive (cooperative) way involves teacher's endeavours to perceive accurately student's positions and motivation, recognise the legitimacy of each other's interests, and search for a solution accommodating the needs of both sides. 


\section{References}

Aramavičiūtè, V. (2005). Auklèjimas ir dvasinè asmenybès branda. [The nurturing and spiritual maturity of personality]. Vilnius: Gimtasis žodis.

Archambault, I., Kurdi, V., Olivier, E., \& Goulet, M. (2016). The joint effect of peer victimization and conflict with teachers on student engagement at the end of elementary school. Merrill-Palmer Quarterly, 62(2), 207-232.

Berg, B. L. (2007). Qualitative research methods for the social science. Long Beach: California State University.

Coleman, P. T. (2006). Power and conflict. In The Handbook of Conflict Resolution: Theory and Practice, Morton Deutsch, Peter Coleman and Eric C. Marcus (eds.), (pp. 120-143). San Francisco: Jossey-Bass.

Čiuladienè, G. (2013). Paaugliu konfliktai ir ju sprendimas ugdymo realybejje. [Adolescent conflicts and their resolution in educational reality]. Vilnius: Mykolo Romerio universitetas.

Davidson, J. A., McElwee G., \& Hannan G. (2004). Trust and power as determinants of conflict resolution strategy and outcome satisfaction. Peace \& Conflict, 10(3), $275-292$.

Dogan, S. (2016). Conflicts management model in school: A mixed design study. Journal of Education and Learning, 5(2), 200-219.

Euwema, M. C., van de Vliert, E., \& Bakker, A. B. (2003). Substantive and relational effectiveness of organizational conflict behavior. International Journal of Conflict Management, 14(2), 119-139.

Ficarra, L., \& Quinn, K. (2014). Teachers' facility with evidence-based classroom management practices: An investigation of teachers' preparation programmes and in-service conditions. Journal of Teacher Education for Sustainability, 16(2), 7187. doi: 10.2478/jtes-2014-0012

Furlong, G. T. (2005). The conflict resolution toolbox: Model \& maps for analyzing, diagnosing and resolving conflict. Mississauga: John Wiley.

Gross, M. A., \& Guerrero, L. K. (2000). Managing conflict appropriately and effectively: An application of the competence model to Rahim's organizational conflict styles. The International Journal of Conflict Management, 11(3), 200-226.

Horan, S. M., Chory, R. M., \& Goodboy, A. K. (2010). Understanding students' classroom justice experiences and responses. Communication Education, 59(4), 453474.

Johnson, D. W., \& Johnson, R. T. (2006). Peace education for consensual peace: The essential role of conflict resolution. Journal of Peace Education, 3(2), 147-174.

Johnson, D. W., \& Johnson, R. T. (1994). Constructive conflict in the schools. Journal of Social Issues, 50(1), 117-137.

Kalaitzidis, D. (2012). Sustainable School Indicators: Approaching the Vision through the Sustainable School Award. Journal of Teacher Education for Sustainability, 14(2): 168-180. doi: 10.2478/v10099-012-0015-7

Kuurme, T., \& Carlsson, A. (2010). The Factors of Well-Being in Schools as a Living Environment according to Students' Evaluation. Journal of Teacher Education for Sustainability, 12(2), 70-88. doi: 10.2478/v10099-009-0055-9

Longaretti, L., \& Wilson, J. (2006). The Impact of Perceptions on Conflict Management. Educational Research Quarterly, 29(4), 3-15. 
Makarevičs, V. (2008). Professional competences of future teachers: Perspective of different evaluators and contexts. Journal of Teacher Education for Sustainability, 10, 68-78. doi: 10.2478/v10099-009-0026-1

Mayer, B. (2000). The Dynamics of Conflict Resolution. San Francisco: Jassey-Bass.

Mitakidou, S., \& Tamoutseli, K. (2011). Engaging Learners in Cooperative Learning through Environmental and Cross-Cultural Activities. Journal of Teacher Education for Sustainability, 13(1), 5-18. doi: 10.2478/v10099-011-0001-5

Ohbuchi, K., Fukushima, O., \& Tedeschi, J. T. (1999). Cultural values in conflict management. Goal orientation, goal attainment and tactical decision. Journal of cross-cultural psychology, 1(30), 51-71.

Okeke, Ch. I., \& Mtyuda, P.N. (2017). Teacher job dissatisfaction: Implications for teacher sustainability and social transformation. Journal of Teacher Education for Sustainability, 19(1), 54-68. doi: 10.1515/jtes-2017-0004

Ortega, J. L. G., \& Fuentes, A.R. (2015). Communication skills training in trainee primary school teachers in Spain. Journal of Teacher Education for Sustainability, 17(1), 86-98. doi: 0.1515/jtes-2015-0007

Ozgan, H. (2016). The usage of domination strategies in conflicts between the teachers and students: A case study. Educational Reseach and Reviews, 11(4), 146-152. doi: 10.5897/ERR2015.2542

Pagliaro, M. M. (2011). Educator or Bully?: Managing the 21st-century classroom. United Kingdom: Rowman \& Littlefield Education.

Rahim, A. M. (1986). Referent role and styles of handling interpersonal conflict. Journal of Social Psychology, 126, 78-96.

Sakk, M. (2013). Coping at school - academic success or/and sustainable coping in future? Journal of Teacher Education for Sustainability, 15(1), 84-106. doi: 10.2478/ jtes-2013-0006

Sauquet, A., \& Bonet, E. (2003). Implications of National Cultural Impacts for Conflict Resolution and Team Learning in Spain: Observations from a Comparative Case Study. Advanced in Developing Human Resources, 5(1), 41-63. doi: 10.1177/15234 22302239182

Tjosvold, D., Hui, C., \& Law, K. S. (2001). Constructive conflict in China: Cooperative conflict as bridge between East and West. Journal of World Business, 36(2), 16683.

Van de Vliert, E., Ohbuchi, K., van Rossum, B., Hayashi, Y. S., \& van der Vegt, G. (2004). Conglomerated Contending by Japanese Subordinates. International Journal of Conflict Management, 15(2), 192-207.

Wilmot, W., \& Hocker, J. (2001). Interpersonal Conflict. New York: McGrawHill.

Correspondence concerning this paper should be addressed to Grazina Ciuladiene, Assoc. Prof., Institute of Education Sciences and Social Work, Mykolas Romeris University, Ateities st. 20 LT-08303 Vilnius. Email: grazina.ciuladiene@mruni.eu 